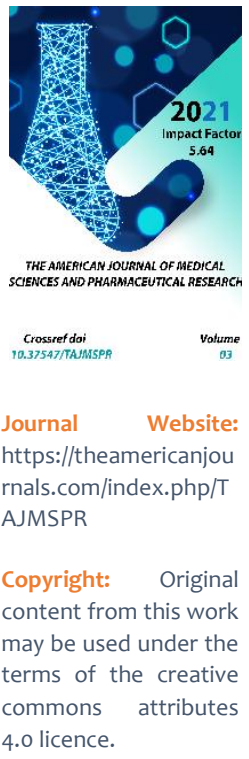

\title{
Morphological Parameters Of Kidney In Polypragmasia With Anti-Inflammatory Drugs
}

\author{
Zafarjon M. Mustafoev
}

Assistant Of The Department Of Anatomy, Clinical Anatomy, Samarkand State Medical Institute, Samarkand, Uzbekistan

\section{ABSTRACT}

We studied macro and microscopic changes in kidney tissue against the background of polypharmacy when modeling renal pathology. It has been shown that the simultaneous use of more than 5 drugs has a nephrotoxic effect on the proximal renal tubules. On macroscopic examination, the kidneys were bean-shaped, the capsule was smooth; with the help of a magnifying glass, it was smooth, shiny, without visible differences. Microscopically, in the kidney tissue in the study group, some structural differences were revealed, the nature and severity of which depended on the type of active drug. In the glomerular apparatus of the kidneys of rats, focal infiltration of mesangial cells was noted. Moreover, in the direct tubules of the kidney apparatus, remarkable changes were not revealed. Thus, it was concluded that tubular damage leads to impaired tubular reabsorption, proteinuria, the morphological criteria of steatosis, and dysproteinosis of varying degrees.

\section{KEYWORDS}

Polypharmacy, Kidney, Morphological Aspects.

\section{INTRODUCTION}

As the central organ of the excretory system, the kidney performs an essential function of maintaining the constancy of the internal environment of the body and takes part in its regulatory mechanisms. The complex functions of the permanent human kidney are provided by the interconnected and interdependent function of the generations of nephrons and collecting ducts, which have features of the structure of the renal tubules, their length, depth in the cortex, and medulla, relative position, blood supply. The integrative 
relationships of the nephrons in conjunction with the collecting ducts provide the overall excretory function of the kidney.

Purpose of the study: To study the macroscopic and microscopic changes in the parameters of the renal nephron when modeling renal pathology.

\section{MATERIALS AND METHODS}

An experimental simulation study with polypharmacy has been studied in laboratory rats. For this purpose, rats with the simultaneous use of up to 5 types of antiinflammatory drugs in the kidney tissue revealed morphological changes. The rats were divided into two groups: 1st control, 15 cases were not exposed to NSAIDs (nonsteroidal anti-inflammatory drugs); 2-nd study 15 cases, within 10 days was prescribed NSPP. Then the animals were dissected; for morphology, one piece of tissue was taken from the kidneys, then fixed in 10\% formalin, standard paraffin wiring was carried out and embedded in paraffin. 5-7 mm thick sections were prepared from the paraffin blocks. The preparations were stained with hematoxylineosin, picrofuchsin according to Van Gieson.

\section{RESULTS}

In both groups, at the macroscopic examination, the kidneys were bean-shaped, the capsule was smooth, with the help of a magnifying glass, it was smooth, shiny, without visible differences. Microscopically, in the kidney tissue in the study group, some structural differences were revealed, the nature and severity of which depended on the type of active drug. In the glomerular apparatus of the kidneys of rats, focal infiltration of the capsule epithelium, podocytes, and macrophages, semi-lunar formations appeared. Moreover, in the tubules of the renal apparatus, alternative changes were noted, represented by dystrophy and necrosis. In the lumens of the tubules and the cytoplasm of the tubule, nephrocytes are swollen and granular, the contours are not precise, in a few, the served epithelium was determined, their nuclei were colored differently. When staining with picrofuchsin, according to Van Gieson, a thickening of the basement membrane of the tubules and glomeruli was revealed. From the duration of the preparations, where polypharmacy was modeled, these changes began to increase, and lymphoma-macrophage infiltration was noted, indicating the development of necrotic changes.

An increase in the number of lymphoid cells, an increase in mucus secretion by kidney cells, and its release in the lumen of the tubules were noted. When analyzing histological preparations, a pronounced heteromorphism of the structure of the kidneys was noted. In places, the glomeruli were deformed. Most of the cells showed signs of degenerative changes. Tissue edema was accompanied by local desquamation of nephrocytes. In some places, necrotic changes in tissue structures occurred (Fig. 1) 


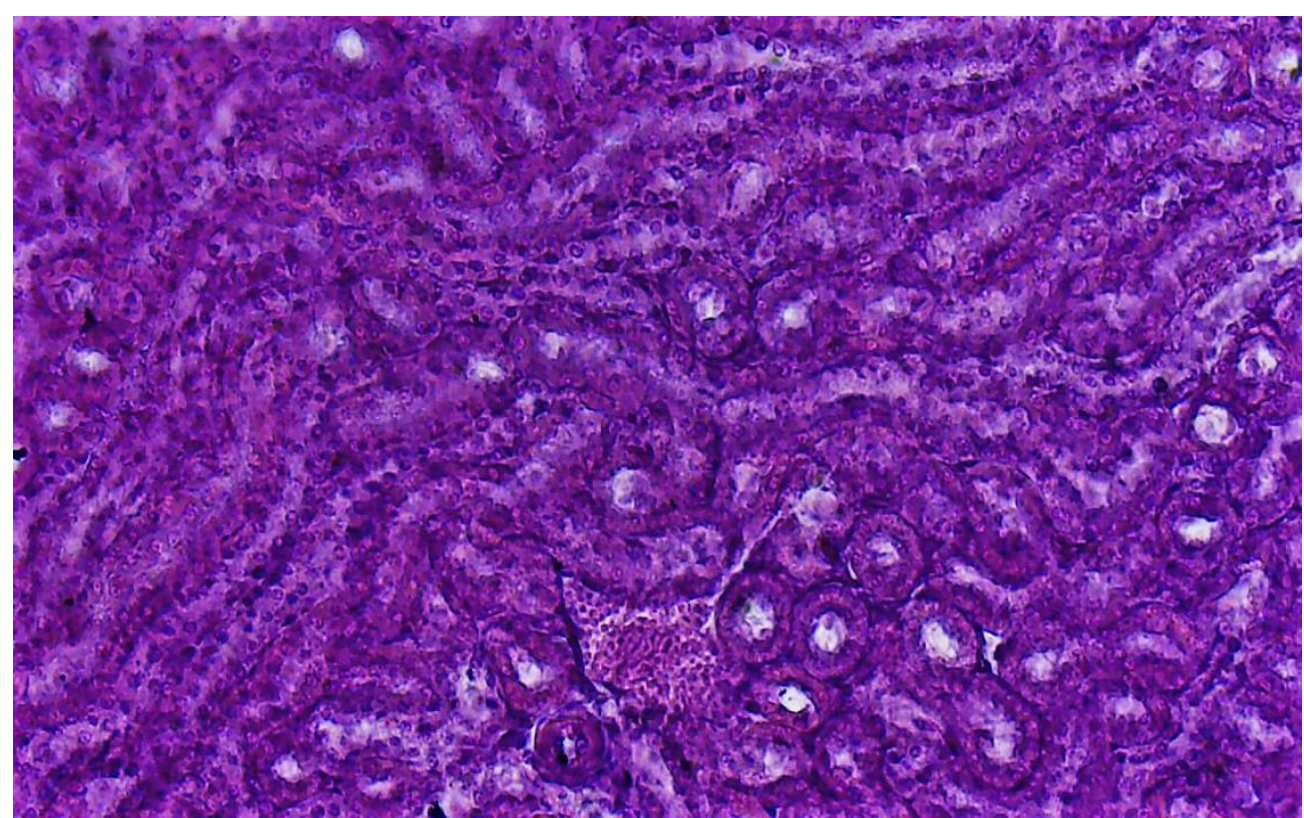

Fig 1. In the kidney tissue, edema and plethora with necrobiotic changes are noted. Hematoxylineosin staining, $10 \times 10$.

Morphometry of the kidney tissue revealed a decrease in the height of the glomerular apparatus and the width of the convoluted tubules of the kidneys by $11.5 \%(P \leq 0.05)$ in the second, by $15.2 \%(P \leq 0.05)$ in the third, and by $18.6 \%(P \leq 0.05)$ in the fourth group, compared with the control, the depth and width of the convoluted tubules of the kidneys also decreased over time in all groups, respectively. The width of the convoluted tubules of the kidneys in the control group of animals in the middle section of the kidney tissue is on average $25.15 \pm 0.22$. In the second group, the width of the tubules decreased on average to $22.01 \pm 0.75$; in the third group of animals, the thickness of the convoluted was $21.01 \pm 0.75$, and in the fourth group decreased to $19.21 \pm$ 0.4243 microns.

In the experimental group, an increase in the number of nephrocytes by $50.14 \%(P \leq 0.05)$ was observed; the glomeruli were in a collapsed state, while their average area practically did not change. 


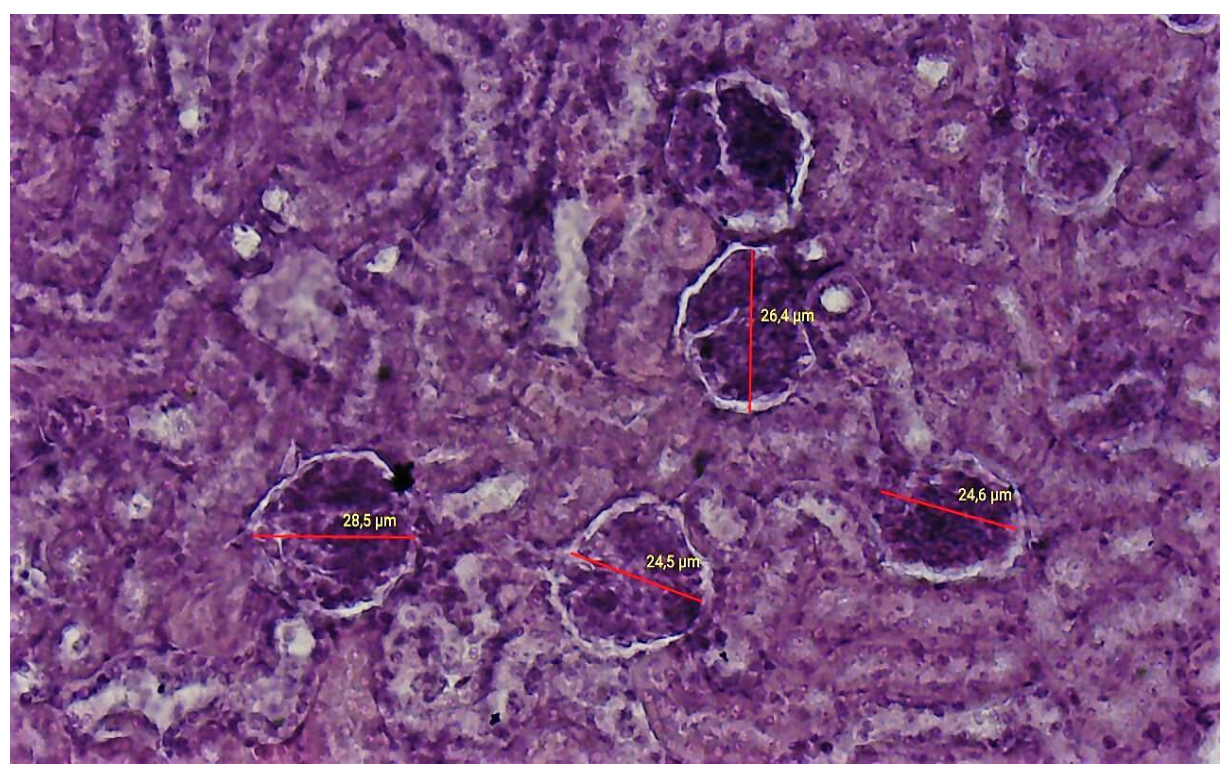

Rice. 2. In the kidney tissue, focal infiltration with necrobiotic changes is noted, the glomerular apparatus of the kidney is in a collapsed state. Hematoxylin-eosin staining, $10 x 10$.

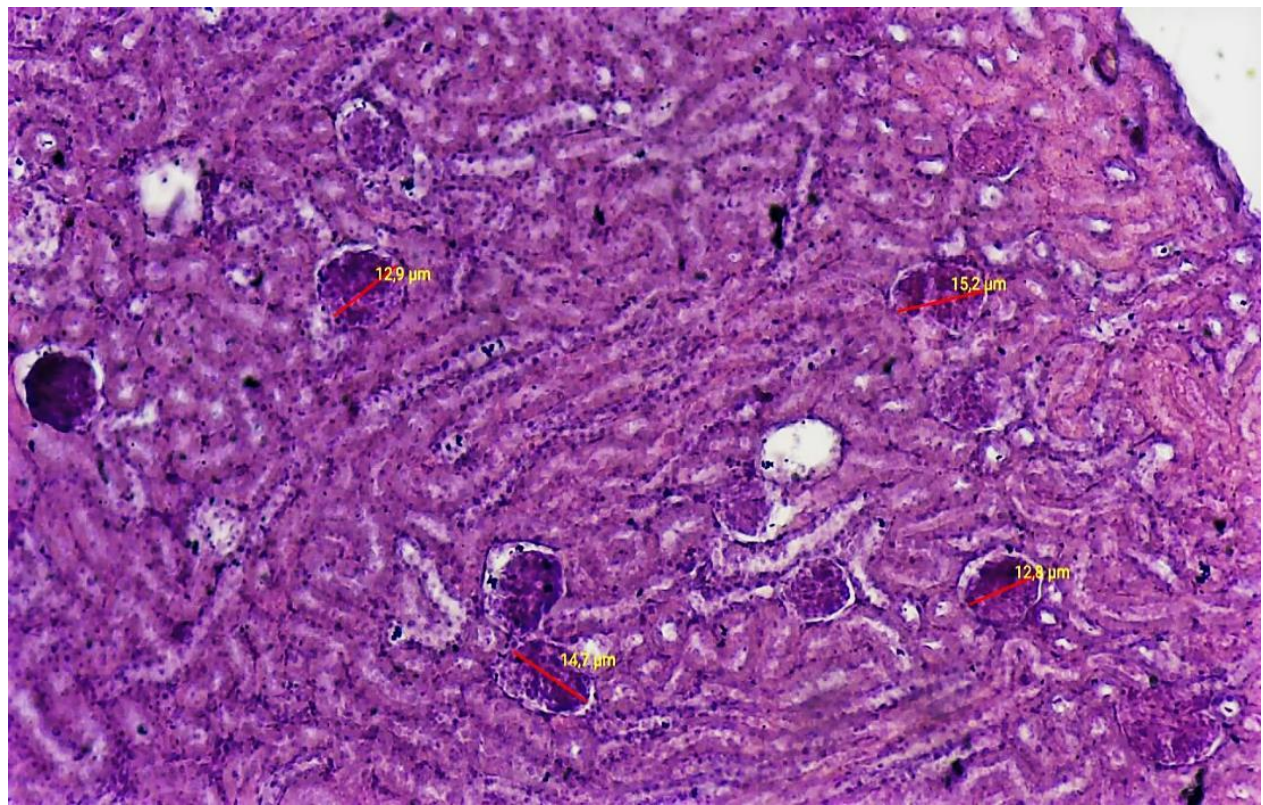

Fig 3. In places the glomeruli were deformed, the heteromorphic structure of the kidneys was expressed. Hematoxylin-eosin staining, $10 \times 10$.

There was plethora and leukocyte infiltration of the pelvis and calyces, foci of necrosis of the mucous membrane. The tubules are in a state of dystrophy, and the process was diffuse. When analyzing histological preparations, a pronounced heteromorphism of the kidney structure was noted. In places, the glomeruli were deformed. The epithelium covering the discharged tubules was edematous and significantly infiltrated with 
lymphocytes. Most of the epithelial cells showed signs of degenerative changes. Tissue edema was accompanied by local desquamation of epithelial cells (Fig. 2). In some places, necrotic changes in the tissue structures of the mesangium appeared, which had a focal character.

\section{CONCLUSION}

Thus, the choice of the object of the study was justified by the fact that the morphology of the kidney and its fibrous capsule, despite the rather extensive data in the literature, under conditions of polypharmacy with antiinflammatory drugs in the kidney tissue, alternative changes were noted; with prolonged use, necrotic and sclerotic changes began to progress. We concluded that damage to the convoluted tubules leads to impaired tubular reabsorption, proteinuria, the morphological criteria of steatosis, and dysproteinosis of varying degrees.

\section{REFERENCES}

1. Agapova N.G. (2007). On medicinal gastroduodenal ulcers. Likuvannya Mystetstvo.

2. Gel'fand, B. R., Gur'ianov, V. A., \& Mamontova, O. A. (2007). Prevention of stress-damage to the gastro-intestinal tract of critically ill patients. Infektsii $v$ khirurgii, 5(2), 14-20.

3. Zhuraeva G.B. (2015). Activity of pathomorphological changes in intestinal lymphoid tissue under the influence of acute intestinal infections. Yakutsk Medical Journal, №2 (50) pp 63-67

4. Zhuraeva, G. B., Saidov, A. A., \& Israilov, R. I. (2015). The dependence of morphological and morphometric changes in the mucous membrane in acute intestinal infection on the type of pathogen. Youth Innovative Bulletin, 4(1), 193-195.

5. Mukhin A.S., Nikolaev A.Yu., Varshavsky V.A. (1988). Alcoholic kidney disease. Ter.arch. №6. pp. 79-86.

6. Nikolaev A.Yu. (1990). Kidney damage., Alcoholic disease. Edited by V.S. Moiseev. M: Publishing house of the University of Friendship of Peoples. pp.73-95.

7. Karateev A.E. (2006). Treatment and drug prevention of NSAID gastropathy: basic provisions. Pharmateka, №6 (121). pp. 3745.

8. Paukov V.S. (1994). Alcoholic disease. Arch. Pathology. №1. pp. 38-45.

9. Andersson, T., Cederberg, C., Heggelund, A., \& Lundborg, P. (1991). The pharmacokinetics of single and repeated once-daily doses of 10, 20 and 40mg omeprazole as enteric-coated granules. Drug Investigation, 3(1), 45-52. 